Original Research
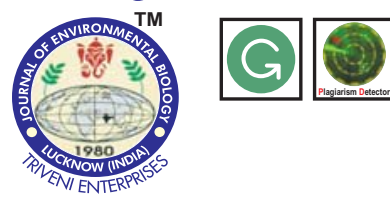

DOI: https://doi.org/10.22438/jeb/38/3/MRN-537

\title{
Sequential elution technique applied to terrestrial mosses: Acclimatization period and replicability
}

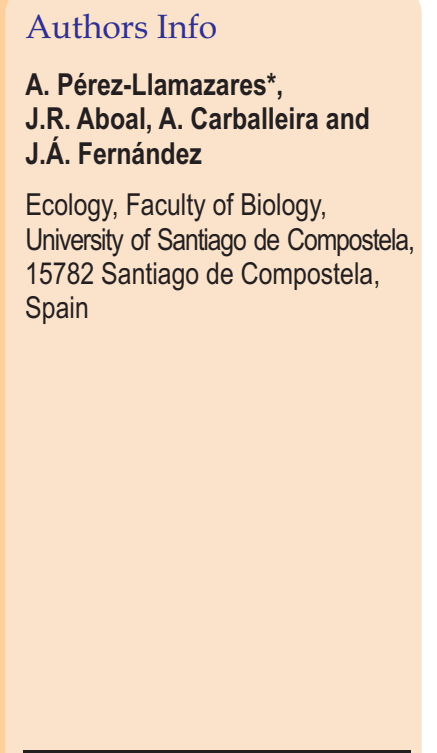

${ }^{*}$ Corresponding Author Email : a.perezllamazares@gmail.com

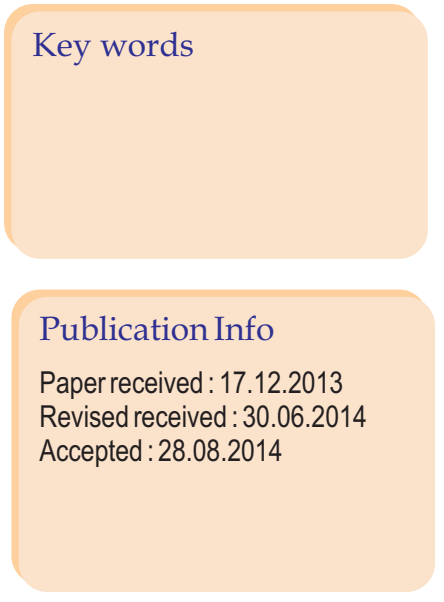

\section{Abstract}

Aim: Use of the Sequential Elution Technique (SET) offers several advantages over measurement of the total concentration of elements in terrestrial mosses, although some methodological problems remain to be resolved. Two such problems were addressed in the present study: the length of the acclimatization period for the moss Pseudocleropodium purum, and the number of analytical replicates required for accurate results.

Methodology: Specimens of Pseudoscleropodium purum were collected from a contaminated and uncontaminated site. Tests were carried out to determine if the acclimatization period allowed the recovery of cell membranes of moss samples subjected to high radiation for different lengths of time (to simulate different states of drought that cause devitalization of moss samples collected at the uncontaminated site). Replicate moss samples (50) from each sampling site were analysed to determine the number of replicates required for accurate measurement of the concentrations of elements in each cell fraction by the SET.

Results: The effect of acclimatization varied depending on the degree of devitalization. It was found that the greater the degree of devitalization, longer the time required to reach the range of $\mathrm{K}$ concentrations at which membrane integrity was $70 \%$. Regarding the number of replicates, with some exceptions, assuming an error of 15 and $20 \%, 5$ and 3 replicates, respectively, were sufficient and the result of the present study does not seem to be affected by the physico-chemical characteristics of the studied elements.

Interpretation: The results indicated that seven day acclimatization period was optimal to allow recovery of the membranes of moss samples subjected to natural desiccation, thus minimizing the possibility of any changes in the distribution of elements in the different cell compartments. Regarding the number of replicates, 5 and 3 replicates were sufficient, assuming error of 15 and $20 \%$, respectively.
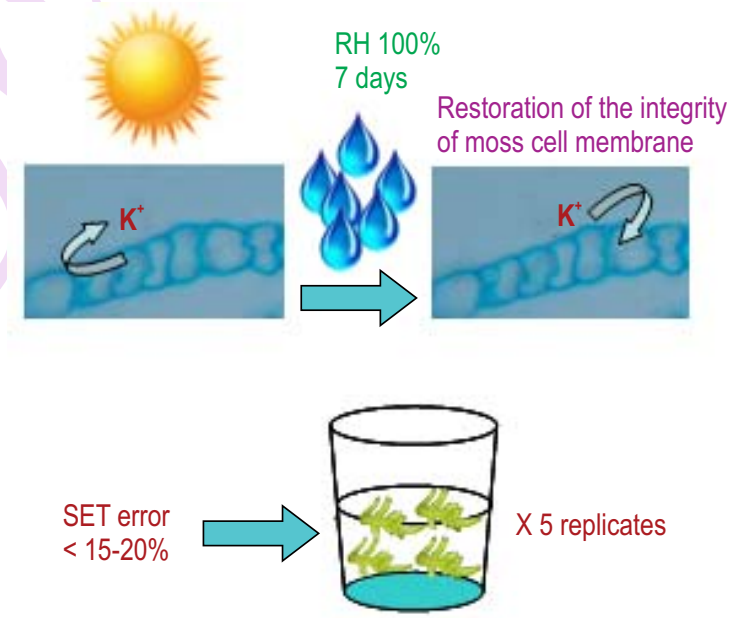


\section{Introduction}

Estimation of the concentrations of contaminants in different cell compartments of terrestrial mosses-organisms, frequently used in air quality biomonitoring (Fernández et al., 2015), is an improvement over the determination of total concentrations of elements, because the former provides information about the cellular location, bioavailability and temporal representativeness of these elements (Pérez-Llamazares et al. 2011a). The Sequential Elution Technique (SET) is used to determine the concentrations of elements in different cell compartments: intercellular, extracellular, intracellular, particulate material (Pérez-Llamazares et al. 2011d).

Despite the advantages offered by the SET, some methodological problems remain to be resolved (PérezLlamazares et al. 2011d). Firstly, the optimal period of acclimatization is unknown for terrestrial bryophytes. The acclimatization period refers to the time that the moss samples should be exposed to a moisture-saturated atmosphere to ensure that the membrane permeability is not altered. Alteration of membrane permeability can lead to erroneous quantification of a portion of the intracellular elements as extracellular elements. The main cause of membrane alteration in terrestrial bryophytes is desiccation of tissues, caused by dry environmental conditions. However, unless severe tissue damage has occurred, such alterations can usually be reversed, by placing the moss samples in moisture-saturated conditions for a certain length of time (Oliver et al. 2005). The length of time used in previous studies is highly variable, ranging between 24 and $168 \mathrm{~h}$ (Brūmelis and Brown 1997; Pérez-Llamazares et al. 2009, 2010). Secondly, the number of analytical replicates required for accurate results to be obtained. is unknown for SET Highly variable results are usually obtained for each sample and are attributed to the heterogeneity of the sample, the extraction procedure and/or analytical errors (Fernández et al. 2004; Pérez-Llamazares et al. 2010). The number of replicates usually used are 3-5 ( Pérez-Llamazares et al. 2011a, Pérez-Llamazares et al. 2009), although this has not been established experimentally.

In light of the above, the optimal period of acclimatization and the use of 3 or 5 analytical replicates in the Sequential Elution Technique was studied.

\section{Materials and Methods}

Sampling and sample processing : Specimens of Pseudoscleropodium purum (Hedw.) M. Fleisch. were collected at a contaminated site, near an aluminium smelter with high emissions of $\mathrm{Cd}$ and $\mathrm{Zn}$, and an uncontaminated sampling site (SS). The samples were cleaned by removing plant remains and adhered material, and the extreme apical sections $(1-1.5 \mathrm{~cm})$ were then separated from the shoots. After a period of acclimatization in a moisture-saturated chamber (Wells and Brown 1990), the samples were washed in double distilled water for $30 \mathrm{sec}$ with shaking, and the excess moisture was then removed by blotting on filter paper.

Determination of the optimal acclimatization period : Moss samples were subjected to high radiation for different lengths of time to simulate different drought conditions that cause devitalization of the samples. Tests were then carried out to determine the length of the acclimatization period required for recovery of cell membranes. The moss samples from the uncontaminated site were first placed in a chamber at low relative humidity at $24{ }^{\circ} \mathrm{C}$ and a luminous flux of $650 \mathrm{Im}$. Aliquots from moss sample were removed after $0,3,6,12,18,24$ and 30 days and then were exposed to saturated moisture conditions for 0,3 , $6,9,12$ and 15 days. The SET was then applied in triplicate to each aliquot representing different combination of exposure.

Study of the replicability of SET : To determine the number of replicates required for accurate measurement of concentrations of elements in each cell compartment, by using SET, the samples collected and processed at each of the two SS were acclimatized for one week. Fifty replicate moss samples from each SS were then analyzed by SET.

Sequential Elution Technique : For determination of optimal acclimatization period, the Sequential Elution Technique developed by Brown and Wells (1988) and modified by Vázquez et al. (1999) was used. For replicability of SET, the most recent modification of SET, proposed by Pérez-Llamazares et al. (2009) was used, this consisted of determining the contaminants directly in the sample rather than in the extracts, thus preventing any analytical interference that may be produced by interactions between the elements and the extractants used. The details of SET extraction protocols has been proposed by PérezLlamazares etal. (2011d).

Chemical analysis : The samples were dried in a forced air oven and homogenized in a ball mill (Retsch ${ }^{\circledR}$ PM 100 in corundum vessels). The concentrations of extra and intracellular $\mathrm{K}$ were determined by flame atomic emission spectrometry (Perkin Elmer 2100). The concentration of $\mathrm{Cd}$ and $\mathrm{Zn}$ were determined in solid suspensions by graphite furnace atomic absorption spectrometry (Perkin Elmer AAnalyst 600). All the samples were determined in duplicate. Parallel analyses were carried out with certified reference material M2 and M3 (Steinnes et al. 1997). In addition, the existence of possible contamination during the analytical process was controlled by using of blanks. The determination of particulate $\mathrm{Cd}$ and part of $\mathrm{Zn}$ corresponding to uncontaminated site were below the limit of quantification, and these data were not taken into account in posterior analyses.

\section{Results and Discussion}

The extracellular-intracellular distribution of $K$ was used to establish the period of acclimatization required to ensure the integrity of moss cell membrane. Alteration of this would lead to 
movement of $\mathrm{K}$ to the exterior of the cell, with consequent increase in its extracellular concentration. Under full membrane integrity, the concentration varie from $10 \%$ to $30 \%$ for $P$. purum (Fernández et al., 2004; Pérez-Llamazares et al., 2011b). In Fig. 1 , each graph shows the ranges of concentrations of $K$ described above, within which it was assumed that the membranes are not altered. The effect of different times of devitalization was tested before beginning the acclimatization period (time of acclimatization: 0 days), before devitalization (Fig. 1 . devitalization 0 days) the moss samples were turgid with normal pigmentation, with no signs of damage and with intracellular $\mathrm{K}$ concentration of $73 \%$, i.e., within the previous range. This level of Kis attributed to the fact that the moss samples were collected in September, after a period of intense rainfall. In the first three days of devitalization, there was a strong decrease in intracellular K (to $39 \%$ ), and thereafter a gradual decrease until the end of the experiment (to $29 \%$ after 30 days). As the devitalization process progressed, the moss samples displayed an increasingly dry appearance, with loss of pigmentation in the apical region and by day 30 the samples were yellow-brown colour. It observed that
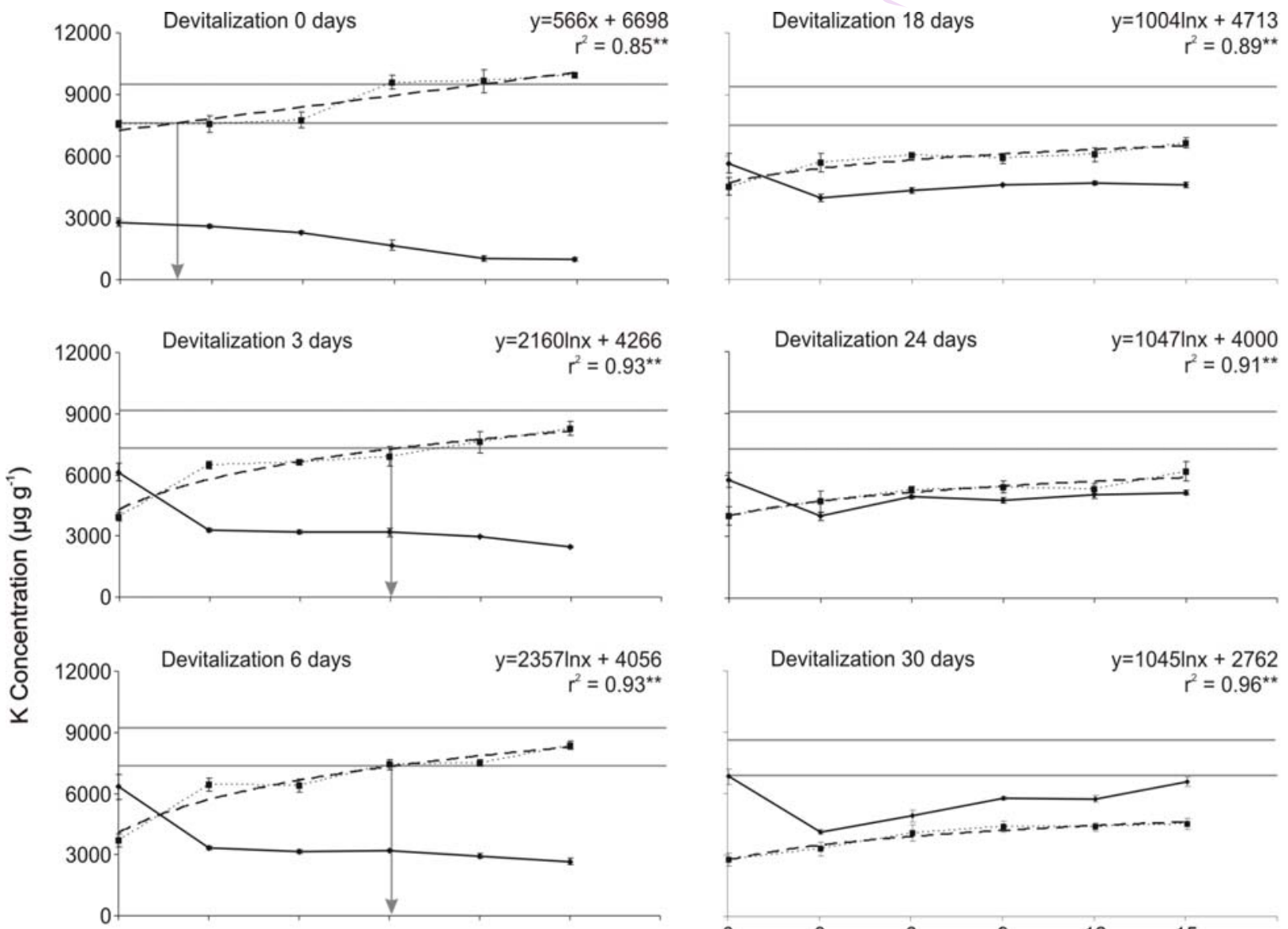

Devitalization 30 days

$y=1045 \ln x+2762$
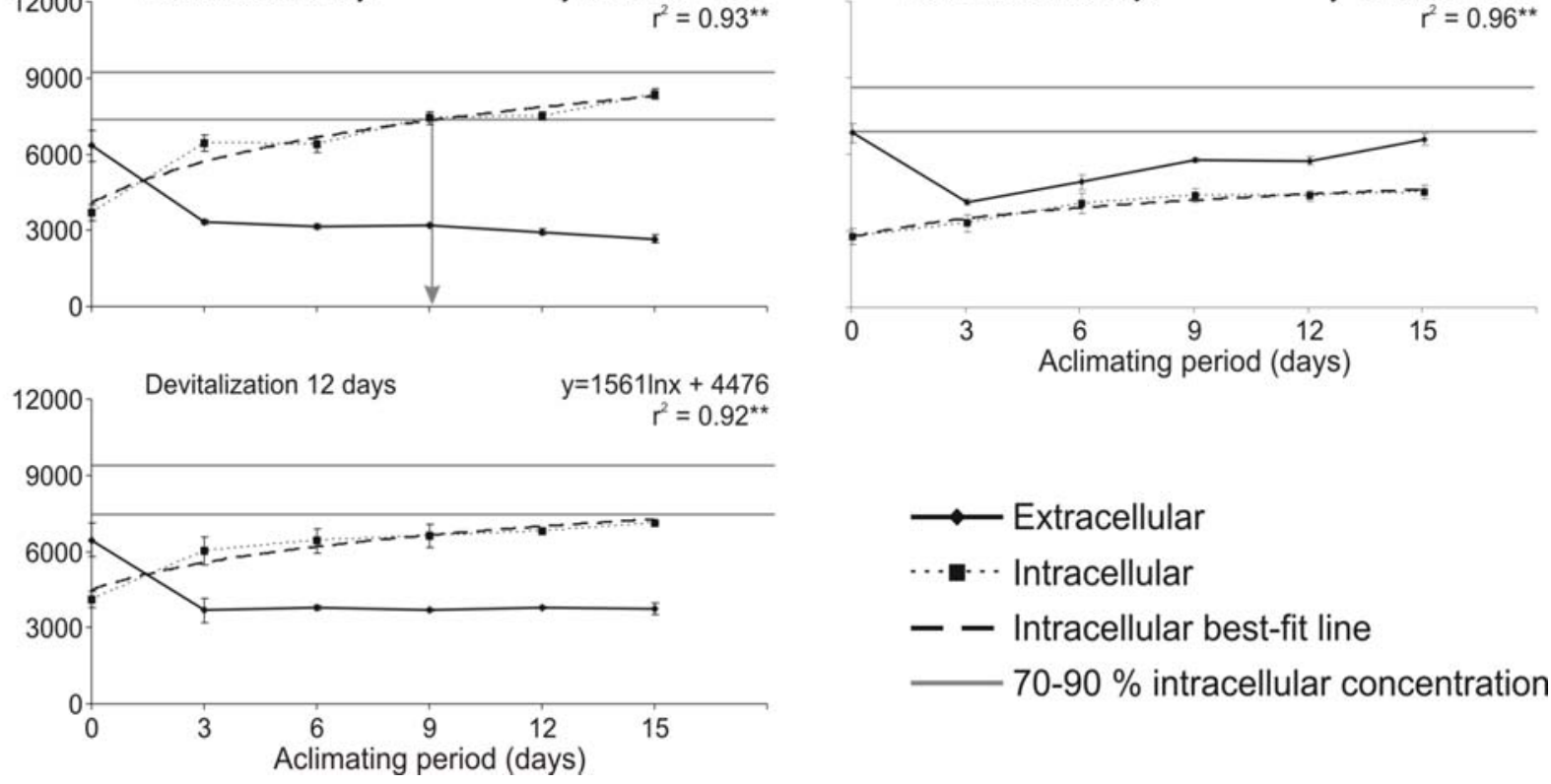

Fig. 1: Concentration of extracellular and intracellular $\mathrm{K}(\mu \mathrm{g} \mathrm{g})$ in relation to the length of the acclimatization period and devitalization period $\left({ }^{* *}: \mathrm{p}<0.01\right)$ 
Table 1: Number of valid replicates. Mean and standard deviation, maximum and minimum value of the Total, Intracellular+Particulate $(I n+P)$ and Particulate $(\mathrm{P})$ concentrations ( $\mathrm{ng} \mathrm{\textrm {g } ^ { - 1 }}$ ) of $\mathrm{Cd}$ and $\mathrm{Zn}$ in samples of Pseudoscleropodium purum from an uncontaminated and contaminated area

\begin{tabular}{|c|c|c|c|c|c|c|c|c|c|c|c|c|}
\hline \multirow{3}{*}{$\begin{array}{l}\text { Error } \\
(\%)\end{array}$} & \multicolumn{6}{|l|}{$\mathrm{Cd}$} & \multicolumn{6}{|l|}{$\mathrm{Zn}$} \\
\hline & \multicolumn{2}{|c|}{ Uncontaminated } & \multirow[b]{2}{*}{$\mathbf{P}$} & \multicolumn{2}{|c|}{ Contaminated } & \multirow[b]{2}{*}{$\mathbf{P}$} & \multicolumn{2}{|c|}{ Uncontaminated } & \multirow[b]{2}{*}{$\mathbf{P}$} & \multicolumn{2}{|c|}{ Contaminated } & \multirow[b]{2}{*}{$\mathbf{P}$} \\
\hline & Total & $\ln +\mathrm{P}$ & & Total & $\ln +P$ & & Total & $\ln +P$ & & Total & $\ln +P$ & \\
\hline$n$ & 50 & 47 & 4 & 50 & 47 & 39 & 50 & 47 & 23 & 48 & 39 & 31 \\
\hline Mean & 106 & 36 & 56 & 293 & 123 & 24 & 43687 & 39222 & 11038 & 67927 & 26999 & 23853 \\
\hline SD & 5 & 6 & 34 & 24 & 21 & 4 & 2466 & 10152 & 3215 & 9046 & 4505 & 8422 \\
\hline Max & 117 & 53 & 93 & 331 & 170 & 31 & 50706 & 59550 & 15801 & 90854 & 37681 & 43946 \\
\hline Min & 96 & 25 & 21 & 262 & 89 & 14 & 38601 & 20457 & 6073 & 53112 & 19018 & 10663 \\
\hline
\end{tabular}

Table 2: Number of replicates required for different levels of error, for total concentration, intracellular+particulate and particulate concentrations in samples of Pseudoscleropodium purum collected at a contaminated and uncontaminated site

\begin{tabular}{|c|c|c|c|c|c|c|c|c|c|c|c|}
\hline \multirow{3}{*}{$\begin{array}{l}\text { Error } \\
(\%)\end{array}$} & \multicolumn{6}{|l|}{$\mathrm{Cd}$} & \multicolumn{5}{|l|}{$\mathrm{Zn}$} \\
\hline & \multicolumn{2}{|c|}{ Uncontaminated } & \multirow[b]{2}{*}{ Total } & \multicolumn{2}{|c|}{ Contaminated } & \multirow[b]{2}{*}{ Total } & \multicolumn{2}{|c|}{ Uncontaminated } & \multirow[b]{2}{*}{ Total } & \multirow{2}{*}{$\frac{\text { Contaminated }}{\ln +\mathrm{P}}$} & \multirow[b]{2}{*}{$\mathbf{P}$} \\
\hline & Total & $\ln +P$ & & $\ln +P$ & $\mathbf{P}$ & & $\ln +P$ & $\mathbf{P}$ & & & \\
\hline 1 & 98 & 1181 & 250 & 1145 & 1275 & 122 & 2574 & 3259 & 681 & 1070 & 4789 \\
\hline 5 & 4 & 47 & 10 & 46 & 51 & 5 & 103 & 130 & 27 & 43 & 192 \\
\hline 10 & 1 & 12 & 3 & 11 & 13 & 1 & 26 & 33 & 7 & 11 & 48 \\
\hline 15 & 0 & 5 & 1 & 5 & 6 & 1 & 11 & 14 & 3 & 5 & 21 \\
\hline 20 & 0 & 3 & 1 & 3 & 3 & 0 & 6 & 8 & 2 & 3 & 12 \\
\hline
\end{tabular}

under natural conditions, the moss never appeared more devitalized than observed after six days of desiccation in the laboratory.

The effect of acclimatization varied depending on the degree of devitalization to which the sample had been subjected (Fig. 1). When moss was acclimatized without prior devitalization (Fig. 1., devitalization 0 days), the initial concentration of intracellular $\mathrm{K}$ was maintained until sixth day of acclimatization, and increased linearly till it reached $91 \%$ on day 15 . In other cases, although the intracellular concentrations did not vary greatly depending on the degree of devitalization (i.e., 29-44\%), the response to the time of acclimatization did vary (they appeared to fit a logarithmic model). It was found that greater the degree of devitalization, longer the time required to reach the range of concentrations of $\mathrm{K}$ at which membrane integrity is assumed (i.e., 70\%). The intersection between the lower limit of this range and the fit is shown in Fig. 1 for the moss samples devitalized for six days or less. For the moss samples devitalized for $12,18,24$ and 30 days, acclimatization period 17, 47, 65 and 153 days were required. The time of acclimatization was selected on the basis of this intersection with the lower limit, as this represents the shortest possible time. As occurs with $\mathrm{K}$ (e.g. devitalization 0 days), an increase in the time of acclimatization may lead to other elements being translocated to the interior of the cell, overstimating the intracellular concentration at the sampling time (Wells and Brown, 1987). All changes in the cellular location of $\mathrm{K}$ were due to movement of the elements, from the interior to the exterior of the cell or vice versa. Such changes were not due to net loss or gain in the moss samples during the experiment, as the sum of extra and intracellular concentrations scarcely varied in all the samples analyzed $(10210 \pm 217 \mu \mathrm{g} \mathrm{g}$ mean $\pm \mathrm{Cl} 95 \%$ ), and was not related to devitalization or acclimatization.

The concentrations of $\mathrm{Cd}$ and $\mathrm{Zn}$ in different cell fractions were obtained for 50 replicates. To prevent analytical errors, when the error for two analytical determinations for same sample was high the samples were excluded from the analysis. The number of valid replicates and some descriptive statistics are shown in Table 1. The distribution of the concentration of each metal and for each SS and cell location were normal. The number of replicates required on the basis of different levels of error are shown in Table 2. With some exceptions, assuming an error of 15 and $20 \%, 5$ and 3 replicates, are sufficient. This result does not seem be affected by the physico-chemical characteristics of the studied elements (Varela et al., 2015). This number of replicates is commonly used where in which the SET is applied (Pérez-Llamazares et al. 2009; Vázquez et al., 1999; Kropacheva et al., 2017). It is impossible to obtain lower levels of error for operational reasons. The highest errors correspond to the particulate fraction, and reflect the heterogeneity of the concentration of particles in the matrix used. The heterogeneity due to particles may also be included in the extracellular compartment, as this fraction is overestimated due to the particulate material (Pérez-Llamazares et al. 2011c). Despite the advantages of the SET regarding biological 
interpretation of the concentrations of elements in different cell compartments, measurement of total concentrations of the elements requires fewer replicates for the same analytical precision (Table 2).

In conclusion, the results showed that acclimatization period of 7 days was optimal to enable recovery of the membranes of moss samples subjected to natural desiccation, thus minimizing the possibility of any changes in the distribution of elements in different cell compartments. In most cases, assuming errors of 15 and $20 \%$, accurate results were obtained with 5 and 3 replicates (as used in most studies where SET is applied).

\section{Acknowledgment}

The present study was financed by Xunta de Galicia, project 10MDS200001PR.

\section{References}

Brown, D.H. and J.M. Wells: Sequential elution technique for determining the cellular location of cations. In: Methods in Bryology. Proceedings of the Bryological Methods Workshop (Ed.: J.M. Glime). Hattori Bot Lab, Nichinan, pp. 227-233 (1988).

Brūmelis, G. and D.H. Brown: Movement of metals to new growing tissue in the moss Hylocomium splendens (Hedw.) BSG. Ann. Bot., 79, 679-686 (1997)

Fernández, J.A., J.R. Aboal, J.A. Couto and A. Carballeira: Moss bioconcentration of trace elements around a $\mathrm{FeSi}$ smelter: Modelling and cellular distribution. Atmos. Environ., 38, 43194329 (2004).

Fernández, J.A., M.T. Boquete, A. Carballeira and J.R. Aboal: A critical review of protocols for moss biomonitoring of atmospheric deposition: Sampling and sample preparation. Sci. Tot. Environ., 517, 132-150 (2015).

Kropacheva, M., M. Melgunov and I. Makarova: The artificial and natural isotopes distribution in sedge (Carex L.) biomass from the Yenisei River flood-plain. Adaptation of the sequential elution technique. J. Environ. Radioactiv., 167, 180-187 (2017).

Oliver, M.J., J. Velten and B.D. Mishler: Desiccation tolerance in bryophytes: Areflection of the primitive strategy for plant survival in dehydrating habitats. Integr. Comp. Biol., 45, 788-799 (2005).

Pérez-Llamazares, A., J.R. Aboal, A. Carballeira and J.A. Fernández: Cellular location of $\mathrm{K}, \mathrm{Na}, \mathrm{Cd}$ and $\mathrm{Zn}$ in the moss Pseudoscleropodium purum in an extensive survey. Sci. Total Environ., 409, 1198-1204 (2011a)

Pérez-Llamazares, A., J.R. Aboal, J.A. Fernández and A. Carballeira: Sequential elution technique in moss Pseudoscleropodium purum: comparison between the commonly used extracellular extractant $\mathrm{NiCl}_{2}$ and other new extractants. Water Air Soil Pollut., 215,561-572 (2011b).

Pérez-Llamazares, A., J.A. Fernández, J.R. Aboal and A. Carballeira: A search for an extracellular extractant of $\mathrm{Hg}$ for use in the sequential elution technique with Pseudoscleropodium purum. J. Bryol., 31, 23-29 (2009)

Pérez-Llamazares, A., J.A. Fernández, J.R. Aboal, S. Giordano and A. Carballeira: Evaluation of the efficacy of the sequential elution technique by use of electron microscopy methods. J. Bryol., 33, 54-61 (2011c).

Pérez-Llamazares, A., J.A. Fernández, A. Carballeira and J.R. Aboal: Sequential elution technique applied to cryptogams: A literature review. J. Bryol., 33, 267-278 (2011d).

Pérez-Llamazares, A., C.J. Garbán-Malagón, J.R. Aboal, J.A. Fernández and $A$. Carballeira: Evaluation of cations and chelating agents as extracellular extractants for $\mathrm{Cu}, \mathrm{Pb}, \mathrm{V}$ and $\mathrm{Zn}$ in the Sequential Elution Technique applied to the terrestrial moss Pseudoscleropodium purum. Ecotox. Environ. Safe., 73, 507-514 (2010).

Steinnes, E., A. Rüling, H. Lippo and A. Mäkinem: Reference materials for large-scale metal deposition surveys. Accreditat. Qual. Assur., 2, 243-249 (1997)

Varela, Z., J.R. Aboal, A. Carballeira, C. Real and J.A. Fernández: Influence of the physicochemical characteristics of pollutants on their uptake in moss. Atmos. Environ., 192, 130-135 (2015).

Vázquez, M.D., J. López and A. Carballeira: Modification of the sequential elution technique for the extraction of heavy metals from bryophytes. Sci. Total Environ., 241, 53-62 (1999).

Wells, J.M. and D.H. Brown: Factors affecting the kinetics of intra and extracellular cadmium uptake by the moss Rhytidiadelphus squarrosus. New Phytol., 105, 123-137(1987).

Wells, J.M. and D.H. Brown: Ionic control of intracellular and extracellular $\mathrm{Cd}$ uptake by the moss Rhytidiadelphus squarrosus (Hedw.) Warnst. New Phytol., 116, 541-553 (1990). 